\title{
Desarrollo de ELISA sándwich indirecto para la determinación de antígenos de excreción- secreción de Fasciola hepatica
}

\section{Development of indirect sandwich ELISA for determination of excretory-secretory antigens of Fasciola hepatica}

\section{Libertad Alzamora-Gonzales*, Rinaldo J. Echevarria, Erasmo H. Colona-Vallejos, Miguel A. Aguilar-Luis y Carolina C. de Amat-Herbozo}

Laboratorio de Inmunología, Facultad de Ciencias Biológicas, Universidad Nacional Mayor de San Marcos. Ciudad Universitaria, Av. Venezuela s/n cuadra 34. Lima 1-Perú.

* Autor para correspondencia

Libertad Alzamora-Gonzales: lalzamorag@unmsm.edu.pe

Rinaldo J. Echevarría: rijoechv@gmail.com

Erasmo H. Colona-Vallejos: ecolonav@gmail.com

Miguel A. Aguilar-Luis: ma23aguilar@gmail.com

Carolina C. de Amat-Herbozo: caro.deamat@gmail.com

\begin{abstract}
Resumen
La fasciolosis es una parasitosis cosmopolita de importancia médico-veterinaria ocasionada por Fasciola hepatica, que afecta al ganado ovino, caprino y vacuno; y accidentalmente al hombre ocasionando una infección endemo-epidémica de difícil diagnóstico. El objetivo fue desarrollar un ELISA sándwich indirecto, empleando 3 anticuerpos, para identificar antígenos de secreción-excreción de Fasciola hepatica (ESFh). Para el ELISA se emplearon anticuerpos policlonales de ratón anti ESFh como anticuerpos de captura, y anticuerpos policlonales de conejo anti ESFh como anticuerpos de detección, a las concentraciones de 10 y $5 \mu \mathrm{g} / \mathrm{mL}$, respectivamente. Como conjugado se emplearon anticuerpos monoclonales de ratón anti-inmunoglobulinas totales de conejo ligado a peroxidasa (1/1000). Se analizaron 31 muestras de heces de ganado ovino y los resultados se compararon con los obtenidos por el examen coproparasitológico directo (CD) y contrainmunoelectroforesis (CIEF). El límite de detección obtenido para ELISA sándwich indirecto fue $100 \mathrm{ng} / \mathrm{mL}$. La prueba presentó una sensibilidad de 100\%, especificidad de $96.6 \%$ y valores predictivos positivos y negativos de $50 \%$ y $96.6 \%$ respectivamente; con relación al examen CD. Al comparar ELISA tipo sándwich indirecto con CIEF se obtuvo una especificidad de $93.5 \%$ y un valor predictivo negativo del $100 \%$. Se concluye que la prueba de ELISA sándwich indirecto diseñada es capaz de detectar antígenos metabólicos en muestras de heces de ovino y se puede utilizar para el diagnóstico Fasciola hepatica.
\end{abstract}

Palabras clave: Inmunodiagnóstico de Fasciola hepática; ELISA sándwich; antígenos de excreción-secreción; alicuya; Fasciola hepatica.

\section{Abstract}

Fasciolosis is a cosmopolitan parasitosis medical-veterinary importance caused by Fasciola hepatica, which affects sheep, goats and cattle; and it affects man accidentally causing an epidemic-endemic infection difficult to diagnose. The aim was to develop an indirect sandwich ELISA with 3 antibodies for detecting excretory-secretory antigens of Fasciola hepatica (ESFh). For the development of indirect sandwich ELISA were used, as capture antibody, mouse polyclonal antibodies anti ESFh and polyclonal antibodies rabbit anti-ESFh as detection antibody, at the concentrations of 10 and $5 \mu \mathrm{g} / \mathrm{mL}$ respectively. The conjugate used was mouse monoclonal anti- total immunoglobulins rabbit linked to peroxidase (1/1000). Were analized 31 sheep fecal samples, and the results were compared with those obtained by direct coproparasitological examination (DC) and counterimmunoelectrophoresis (CIEP). The detection limit obtained for indirect sandwich ELISA was $100 \mathrm{ng} / \mathrm{mL}$. The test had a $100 \%$ sensitivity, $96.6 \%$ specificity, positive and negative predictive values of $50 \%$ and $96.6 \%$ respectively, in relation to DC test. Comparing with CIEP the specificity obtained for indirect sandwich ELISA was $93.5 \%$ and a negative predictive value of $100 \%$. We concluded that indirect sandwich ELISA designed is able to detect metabolic antigens in ovine feces samples and can be used for Fasciola hepatica diagnosis

Keywords: Fasciola hepatica inmunodiagnosis; sandwich ELISA; excretory-secretory antigens; alicuya; Fasciola hepatica.

\section{Citación:}

Alzamora-Gonzales L., R.J. Echevarria, E.H. Colona-Vallejos, M.A. Aguilar-Luis y C.C. de Amat-Herbozo. 2016. Desarrollo de ELISA sándwich indirecto para la determinación de antígenos de excreción-secreción de Fasciola hepatica. Revista peruana de biología 23(1): 047 - 052 (Abril 2016). doi: http://dx.doi.org/10.15381/rpb.v23i1.11833

Presentado: $\quad$ 23/09/2015

Aceptado: $\quad 18 / 02 / 2016$

Publicado online: $28 / 05 / 2016$
Fuentes de financiamiento: Este trabajo fue financiado por el CONCYTEC (PROCYT-2006) y el Vicerrectorado de Investigación de la Universidad Nacional Mayor de San Marcos.

\section{Información sobre los autores:}

LAG, ECV: diseñaron el estudio; RJE, ECV, CdA: desarrollaron los experimentos; MAL: recolectó las muestras para el análisis coproparasitológico; LAG, RJE, ECV: analizaron e interpretaron los datos; LAG ECV: redactaron el manuscrito; LAG, ECV, RJE: revisaron y aprobaron el manuscrito.

Los autores no incurren en conflictos de intereses.

Journal home page: http://revistasinvestigacion.unmsm.edu.pe/index.php/rpb/index

(c) Los autores. Este artículo es publicado por la Revista Peruana de Biología de la Facultad de Ciencias Biológicas, Universidad Nacional Mayor de San Marcos. Este es un artículo de acceso abierto, distribuido bajo los términos de la Licencia Creative Commons Atribución-NoComercial-Compartirlgual 4.0 Internacional.(http://creativecommons.org/licenses/by-nc-sa/4.0/), que permite el uso no comercial, distribución y reproducción en cualquier medio, siempre que la obra original sea debidamente citadas. Para uso comercial, por favor póngase en contacto con editor.revperubiol@gmail.com. 


\section{Introducción}

Fasciola hepatica, es un parásito cosmopolita de importancia médico-veterinaria que afecta a la ganadería lechera con prevalencias superiores al $80 \%$ generando significativas pérdidas económicas (Espinoza et al. 2010, Rivera et al. 2010, AbouEl-Doubal et al. 2015). La heterogénea sintomatología clínica ocasionada por la fasciolosis en el ganado, no facilita la detección de la enfermedad en una etapa inicial, ni permite diferenciarla de otras parasitosis. La determinación clásica de la fasciolosis se realiza por exámenes coproparasitológicos, que no podrían aplicarse durante la fase aguda o período prepatente de la enfermedad, otro factor que influye en el diagnóstico es la excreción intermitente de los huevos del parásito (Maleewong et al. 1999).

Se han desarrollado métodos inmunoserológicos basados en la detección de anticuerpos como una alternativa para el diagnóstico, sin embargo las desventajas son que no se puede diferenciar una infección pasada de una reciente (Espino et al. 1998, Espinoza et al. 2010) y las reacciones cruzadas con otros parásitos (Cornelissen et al. 1999, Carnevale et al. 2001). En los últimos años se han descrito inmunoensayos basados en la detección de antígenos mediante los cuales es posible diferenciar la infección activa y la etapa prepatente (Estuningsih et al. 2009, Shafiei et al. 2015).

En el Perú se han utilizado los métodos serológicos Fas2-ELISA, Western blot y Arco 2, para la detección de anticuerpos específicos en suero de personas con fasciolosis (Maco et al. 2002, Marcos et al. 2007, Espinoza et al. 2010, Escalante et al. 2011); de los cuales el método Fas2-ELISA ha sido utilizado para el diagnóstico de fasciolosis en el ganado bovino (Valencia et al. 2005).

Los exámenes coproparasitológicos y la prueba serológica Fas2-ELISA, han permitido conocer que existen altas tasas de infección con Fasciola hepatica en los pobladores y el ganado ovino y bovino residentes en las diferentes localidades rurales de nuestro país (Maco et al. 2002, Valencia et al. 2005; Marcos et al. 2007, Espinoza et al. 2010), pero se ha comprobado que con estas metodologías sólo se puede diagnosticar la fasciolosis en la fase crónica; por lo cual no son de utilidad para empezar y monitorear un tratamiento eficaz con drogas antihelmínticas (Sánchez-Andrade et al. 2001, Espinoza et al. 2010, Ticona et al. 2010). Por lo tanto, es importante contar con herramientas de diagnóstico, como las técnicas de captura, que permitan la identificación de bajas concentraciones de antígeno en la muestra y por ende la identificación temprana del parásito.

\section{Material y métodos}

Preparación de antígenos de excreción-secreción de Fasciola bepatica (Ag ESFh).- Las fasciolas vivas fueron colectadas y lavadas en solución salina amortiguadora de fosfatos (SSAF) estéril, pH 7.2. Posteriormente se colocaron en medio RPMI 1640 con $100 \mu \mathrm{g} / \mathrm{mL}$ de estreptomicina y $100 \mu \mathrm{g} / \mathrm{mL}$ de ampicilina e incubaron a $37^{\circ} \mathrm{C}$ durante 24 horas. Los antígenos metabólicos de Fasciola hepática se colectaron a $4{ }^{\circ} \mathrm{C}$, se filtraron y liofilizaron. La concentración de proteínas se determinó empleando el reactivo de Bradford.

Elaboración de suero hiperinmune.- Se inmunizó una coneja blanca de raza Nueva Zelanda de $2 \mathrm{Kg}$ de peso y 10 ratonas de la línea Balb/c de 20 - 25 g procedentes del Centro Nacional de Productos Biológicos del Instituto Nacional de Salud (LimaPerú, $11^{\circ} 59^{\prime} 00^{\prime}$ S; 7650’00”W). Se inocularon en la coneja cuatro dosis de $250 \mu$ g de antígenos de excreción-secreción de Fasciola hepatica La primera inoculación fue vía subcutánea empleando el coadyuvante completo de Freund (CCF) y las tres restantes fueron inoculadas vía intramuscular empleando el coadyuvante incompleto de Freund (CIF).

Del mismo modo, se inocularon las ratonas con tres dosis de $50 \mu \mathrm{g}$ de antígenos de excreción-secreción de Fasciola hepática. La primera dosis se inoculó vía subcutánea empleando el coadyuvante completo de Freund (CCF), la segunda dosis fue inoculada vía intramuscular empleando el coadyuvante incompleto de Freund (CIF) y la tercera dosis fue inoculada vía subcutánea empleando el CIF. Para ambos protocolos el intervalo entre cada dosis fue de 15 días. Finalmente entre 10 y 15 días después de administrar la última dosis se realizó la sangría total vía punción cardíaca, se separó el suero y se almacenó a $-20^{\circ} \mathrm{C}$ hasta su uso. La determinación del título de anticuerpos se realizó mediante el inmunoensayo en capa fina (ICF).

Separación de inmunoglobulinas de suero de conejo y de ratón.- Los anticuerpos policlonales anti Ag ESFh (de captura-ratón y detección-conejo) se obtuvieron mediante precipitación por salado utilizando solución saturada de sulfato de amonio (SSSA) al 50 y 45\% respectivamente y seguida de diálisis exhaustiva utilizando bolsas de celulosa con corte de 12 $\mathrm{KDa}$ (Sigma) a $4{ }^{\circ} \mathrm{C}$ durante 24 horas contra solución salina fisiológica (Torrico 2000).

Desarrollo de la prueba ELISA sándwich indirecta.- Se realizó en ocho fases: fase I. Sensibilización de la placa ELISA, se emplearon placas de poliestireno Immulon II que fueron recubiertas con anticuerpos policlonales (anticuerpos de captura) de ratón anti Ag ESFh diluidos en buffer fosfato salino 0.01 M, pH 7.2 (PBS); fase II. Bloqueo con Seroalbúmina bovina al 1\% en PBS (SAB-PBS); fase III. Estandarización de muestras y controles (control negativo: SAB en PBS y control positivo: antígeno de excreción-secreción de Fasciola hepatica en PBS); fase IV. Segundo reconocimiento del antígeno de secreción-excreción de F. hepatica con anticuerpos policlonales de conejo (anticuerpos de detección) diluido en SAB-PBS; fase V. Adición del conjugado con peroxidasa, se emplearon anticuerpos monoclonales de ratón anti-inmunoglobulinas totales de conejo diluidos en SAB-PBS; fase VI. Adición del sustrato y del cromógeno, se empleó peróxido de hidrógeno y una solución tamponada de tetrametilbenzidina (TMB); fase VII. Detención de la reacción con una solución de ácido sulfúrico y fase VIII. Lectura de las placas en un lector de ELISA (ER 500 SINNOWA) a $450 \mathrm{~nm}$. Al final de cada fase, hasta la fase $\mathrm{V}$, se realizaron cuatro lavados con buffer fosfato salino-Tween 20 (PBS-T).

Determinación del límite de detección de antígenos de excreción-secreción de Fasciola hepatica (Ag ESFh) por ELISA sándwich indirecto.- Se hicieron diluciones del Ag ESFh empleando como diluyentes PBS y agua destilada. Las diluciones se prepararon por duplicado, con 2 como factor de dilución, desde la concentración inicial de $25 \mu \mathrm{g} / \mathrm{mL}$ hasta obtener una concentración final de $0.02 \mu \mathrm{g} / \mathrm{mL}$.

Examen coproparasitológico.- Las muestras de heces de ganado ovino criollo (Ovis aries) $(\mathrm{n}=31)$ procedentes del Valle de Condebamba, distrito de Condebamba, Provincia de Cajabamba, departamento de Cajamarca fueron obtenidas por hisopado rectal de cada espécimen y colocadas en bolsas de plástico con 


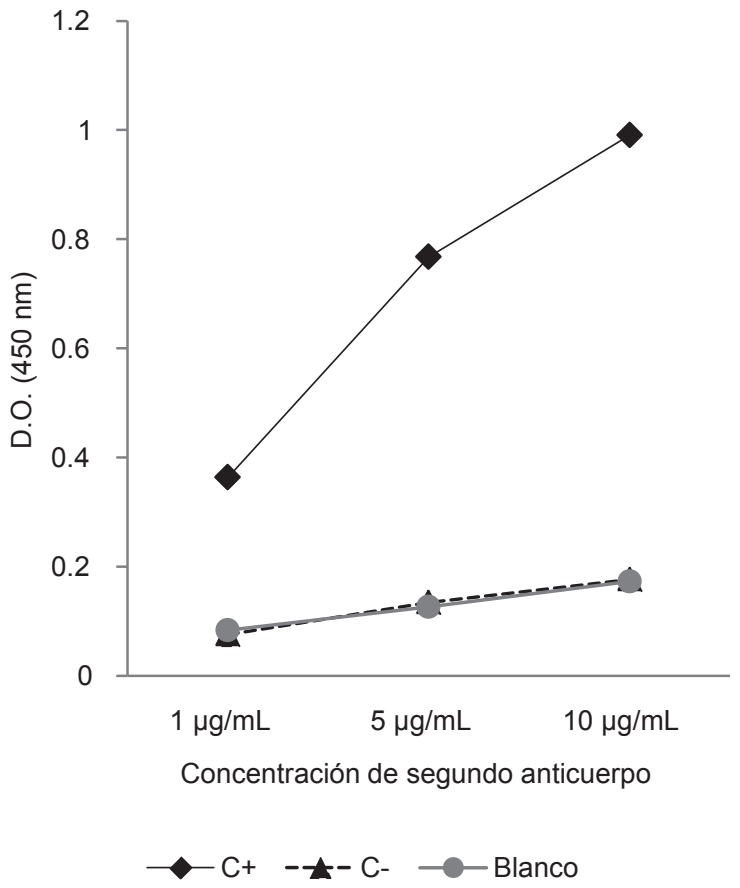

Figura 1. Estandarización del sistema ELISA sándwich indirecto, empleando $10 \mu \mathrm{g} / \mathrm{mL}$ de anticuerpo de captura, tres concentraciones del anticuerpo de detección (1, 5 y $10 \mu \mathrm{g} /$ $\mathrm{mL}$ ) y 1/1000 como dilución del conjugado.

cierre hermético. Se realizó el examen coproparasitológico directo colocando 1 - 2 mg de materia fecal y una gota de suero fisiológico o lugol para determinar las muestras positivas o negativas para fasciolosis (Beltran et al. 2003)

Detección de coproantígenos (Ag ESFh en muestras de heces) por CIEF y ELISA sándwich indirecto.- Las muestras de heces de gano ovino fueron homogenizadas con tres mililitros de agua destilada por cada gramo de heces. Se dejó sedimentar toda la noche a $4{ }^{\circ} \mathrm{C}$ y se recuperó el sobrenadante. Las muestras procesadas se alicuotaron y almacenaron a $-20{ }^{\circ} \mathrm{C}$ hasta su uso. Las muestras procesadas se analizaron en paralelo mediante ELISA sándwich indirecto y contrainmunoelectroforesis (CIEF). La prueba de CIEF se realizó de acuerdo a Morilla y Bautista (1986), con modificaciones.

Punto de corte (Cut off) del ELISA sándwich indirecto.- Las muestras procesadas negativas para fasciolosis, se analizaron por ELISA sándwich indirecto, examen coproparasitológico directo y contrainmunoelectroforesis. Las densidades ópticas (D.O.) obtenidas de las muestras negativas para fasciolosis se utilizaron como valores de control negativo y sirvieron para determinar el punto de corte (Cut off) mediante la fórmula: $\mathrm{X}+2 * \mathrm{SD}$, donde X y SD representan la media muestral y la desviación estándar respectivamente. La fórmula escogida garantizó que el 95\% de los valores de las densidades ópticas obtenidas en las muestras negativas, se encuentren alrededor de su valor promedio.

Análisis de resultados.- Los datos se expresaron como la media aritmética $(\mathrm{X})$, desviación estándar (SD) o porcentaje (\%). Se elaboró tablas de doble entrada, para determinar la especificidad, sensibilidad, valores predictivos positivos y negativos. Para el análisis de los datos, se utilizó los programas informáticos SPSS (versión 17 para Windows) y Microsoft Excel 2003.

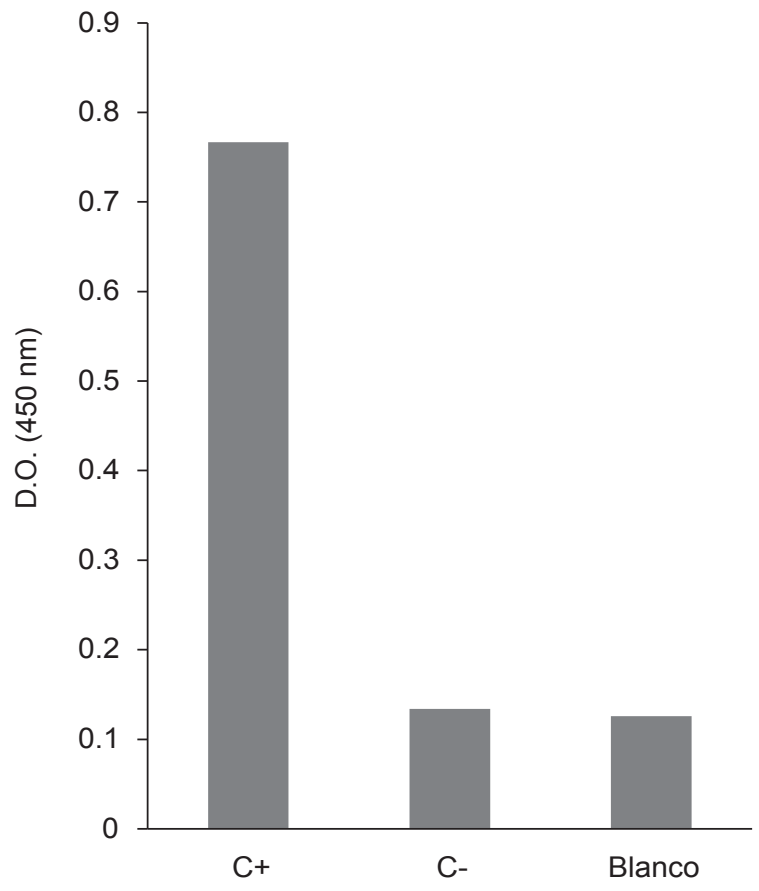

Figura 2. Valores obtenidos para cada uno de los controles (C+ y C-) y el blanco de la prueba, empleando la concentración óptima de anticuerpo de captura, segundo anticuerpo y la dilución óptima del conjugado.

Aspectos éticos.- Los experimentos con los animales fueron desarrollados de acuerdo a la Guide for the care and use of laboratory animals (National Research Council, 2011) y las guías de manejo y cuidado de animales de laboratorio: ratón y conejo (Fuentes et al. 2008, Fuentes et al. 2010).

\section{Resultados}

La concentración óptima del anticuerpo de captura y del anticuerpo de detección fue de $10 \mu \mathrm{g} / \mathrm{mL}$ y $5 \mu \mathrm{g} / \mathrm{mL}$ respectivamente. La dilución óptima del conjugado fue 1/1000 (Fig.1).

En la figura 2 se observa la diferencia entre los valores de densidades ópticas (D.O.) para cada uno de los controles y el blanco de la prueba, empleando la concentración óptima de anticuerpo de captura, de detección y la dilución óptima del conjugado.

El límite de detectabilidad para los Ag ESFh en PBS, por ELISA sándwich fue $100 \mathrm{ng} / \mathrm{mL}$. Respecto a los Ag ESFh en agua destilada, el límite de detectabilidad por ELISA sándwich indirecto fue $780 \mathrm{ng} / \mathrm{mL}$ (Fig. 3).

Para determinar las diferencias entre los valores de las densidades ópticas (D.O.) se compararon los datos obtenidos en las muestras negativas y positivas, con el valor de corte (Cut off) y la D.O. del control positivo de la prueba (Fig. 4) positivas, con el valor de corte (Cut Off) y el control positivo de la prueba (C+).

Al comparar el ELISA sándwich indirecto con el examen coprológico directo, se obtuvo una sensibilidad del 100\%, especificidad del $96.6 \%$, valor predictivo positivo del $50 \%$ y valor predictivo negativo del $96.6 \%$ (Tabla 1 ), mientras que para el ELISA sándwich indirecto con respecto a la CIEF se obtuvo una especificidad de $93.5 \%$ y un valor predictivo negativo del $100 \%$ (Tabla 2). 


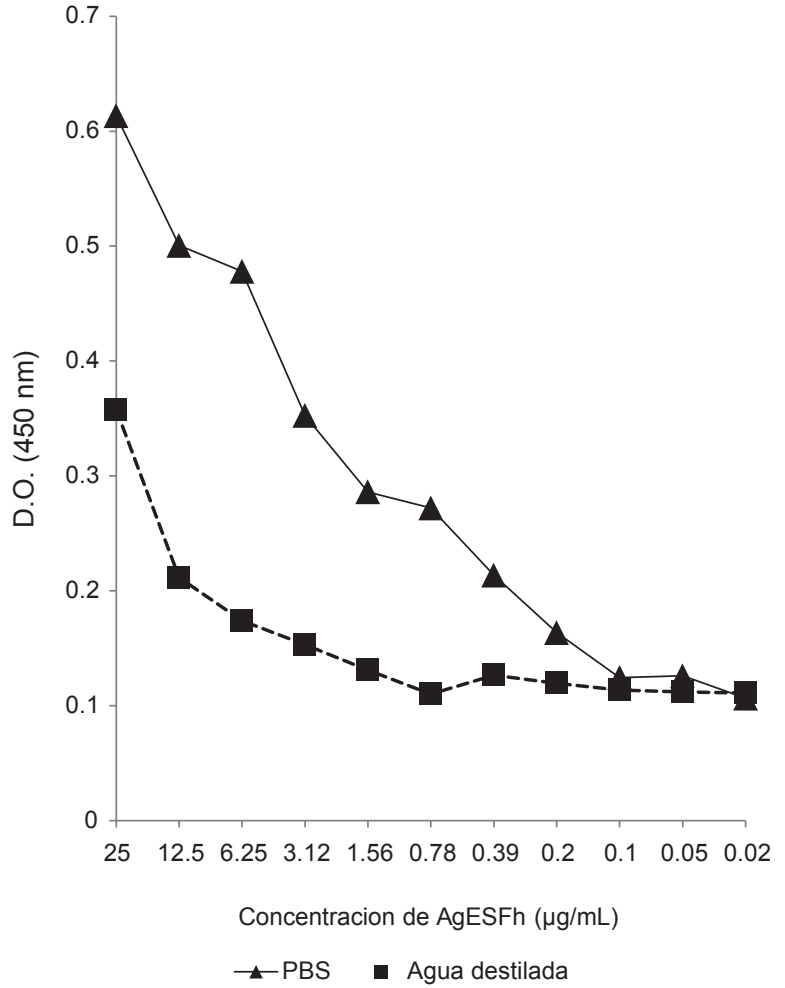

Figura 3. Determinación del límite de detección de antígenos de excreción-secreción de Fasciola hepatica (AgESFh) por ELISA sándwich indirecto.

\section{Discusión}

El ELISA sándwich indirecto propuesto es un sistema de tres anticuerpos, donde el primer anticuerpo es el de captura (anticuerpos policlonales de ratón anti-Ag ESFh) y está adherido al soporte de poliestireno; el anticuerpo de detección es el anticuerpo policlonal de conejo anti-Ag ESFh ratón, que es reconocido por el conjugado (anticuerpos monoclonales de ratón anti-Inmunoglobulinas totales de conejo); se ha ideado un ELISA sándwich indirecto con dos anticuerpos heterólogos, excluyendo posibles reacciones cruzadas.

La concentración óptima para el anticuerpo de captura fue de $10 \mu \mathrm{g} / \mathrm{mL}$ y en el caso del anticuerpo de detección fue de $5 \mu \mathrm{g} /$ $\mathrm{mL}$; respecto a la concentración del anticuerpo de captura Espino et al. (1998) y Estuningsih et al. (2009), emplearon una concentración de $5 \mu \mathrm{g} / \mathrm{mL}$ y $2.5 \mu \mathrm{g} / \mathrm{mL}$ respectivamente. Al evaluar la concentración de $5 \mu \mathrm{g} / \mathrm{mL}$ del anticuerpo de captura se observó claras diferencias entre el control positivo, control negativo y el blanco de la prueba, pero se eligió la concentración de $10 \mu \mathrm{g} / \mathrm{mL}$

Tabla 1. Especificidad, sensibilidad y valores predictivos del ELISA sándwich indirecto con relación al examen coproparasitológico directo para coproantígenos de Fasciola hepatica en ovinos. Donde $\mathrm{Vp}(+)$ : Valor predictivo positivo y $\mathrm{Vp}(-)$ : Valor predictivo negativo.

\begin{tabular}{lc}
\hline & ELISA sándwich \\
\hline$\%$ Sensibilidad & 100 \\
$\%$ Especificidad & 96.6 \\
$\% \mathbf{V p}(+)$ & 50 \\
$\% \mathbf{V p}(-)$ & 96.6 \\
\hline
\end{tabular}

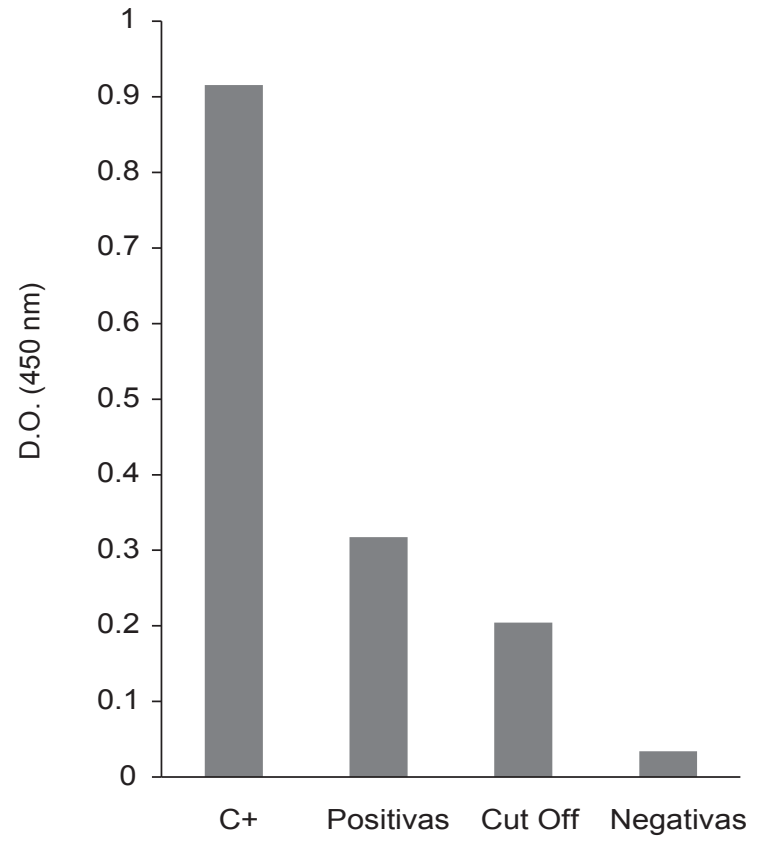

Figura 4. Comparación de los valores de densidades ópticas (D.O.) obtenidos en las muestras de heces negativas y positivas, con el valor de corte (Cut Off) y el control positivo de la prueba $(\mathrm{C}+)$.

como concentración óptima de anticuerpo de captura, debido a que ésta obtuvo el valor más alto de densidad óptica (D.O.) en el control positivo y valores significativamente menores de D.O. en el control negativo y el blanco de la prueba. Estos resultados se relacionan con los estudios antes citados, aunque los autores emplearon anticuerpos monoclonales de ratón de la clase $\mathrm{IgG}$, en contraste con la utilización de anticuerpos policlonales de ratón como anticuerpo de captura en el sándwich ELISA indirecto desarrollado en el presente trabajo.

Además se ha reportado la capacidad de sensibilizar los soportes de poliestireno de manera óptima con concentraciones cercanas a $10 \mu \mathrm{g} / \mathrm{mL}$ (Ochoa et al. 2001). Respecto a los valores de concentración óptima del anticuerpo de detección y el isotipo de anticuerpo a emplear son muy variables en los diferentes sistemas ELISA sándwich. Esta variación se debe a que las características del anticuerpo de detección van a determinar la lectura de la prueba, las cuales se pueden agrupar en tres metodologías: anticuerpos conjugados con peroxidasa, anticuerpos conjugados con biotina y anticuerpos no conjugados, en este caso la lectura de la prueba depende de un anticuerpo monoclonal anti-anticuerpo de detección conjugado con peroxidasa o biotina.

Tabla 2. Especificidad, sensibilidad y valores predictivos del ELISA sándwich indirecto respecto a la Contrainmunoelectroforesis (CIEF) para coproantígenos de Fasciola hepatica en ovinos.

\begin{tabular}{lc}
\hline & ELISA sándwich \\
\hline$\%$ Sensibilidad & 0 \\
$\%$ Especificidad & 93.5 \\
$\% \mathbf{V p}(+)$ & 0 \\
$\% \mathbf{V p}(-)$ & 100 \\
\hline
\end{tabular}


En el presente trabajo se empleó anticuerpos policlonales de conejo anti-Ag ESFh como anticuerpo de detección, y para realizar la lectura de la prueba se empleó una dilución óptima del anticuerpo monoclonal de ratón anti-inmunoglobulina de conejo conjugado con la enzima peroxidasa de 1/1000. Esto permitió diferenciar claramente los controles empleados en el desarrollo del ELISA sándwich indirecto, y del mismo modo las muestras positivas de las muestras negativas. Sánchez-Andrade et al. (2000) emplearon como anticuerpo de detección anticuerpos policlonales de conejo de la clase IgG a una concentración de 0.6 $\mu \mathrm{g} / \mathrm{mL}$ y como conjugado anticuerpos monoclonales anti-IgG de conejo conjugados con la enzima peroxidasa a una dilución de 1/1000; lo cual logró obtener resultados sobresalientes en la detección de antígenos de excreción-secreción de Fasciola hepatica en suero de ovinos.

El límite de detección de antígenos de excreción-secreción de Fasciola hepatica (Ag ESFh) por ELISA sándwich, empleando como diluyente PBS fue de $100 \mathrm{ng} / \mathrm{mL}$ mientras que para $\mathrm{Ag}$ ESFh diluidos en agua destilada (diluyente usado en el procesamiento de muestras de heces), se encontró una disminución del límite de detectabilidad hasta un valor de $780 \mathrm{ng} / \mathrm{mL}$. Ambos límites se determinaron siguiendo el criterio en el cual los valores de absorbancia se mantenían constantes o dejaban de variar significativamente. Diversos autores han reportado que la dilución de las muestras de heces en un tampón salino suplementado con Tween 20, SAB o azida de sodio y en algunos casos agua destilada suplementada con Tween 20, permite obtener valores de absorbancia y límites de detección más altos que evaluando las muestras de heces diluidas sólo con agua destilada o muestras de suero sin diluir; además en estos trabajos se observó que una vez procesadas las muestras de heces pueden ser almacenadas a -20 ${ }^{\circ} \mathrm{C}$ hasta su uso sin ocasionar pérdida en la capacidad antigénica de las proteínas de excreción-secreción de Fasciola hepatica, presentes en las muestras de heces (Espino \& Finlay 1994; Almazán et al. 2001; Mezo et al. 2004; Domenech et al. 2009).

La evaluación del método ELISA sándwich indirecto propuesto, permitió obtener resultados preliminares que sustentan la necesidad de seguir investigando para mejorar el método con fines de poder aplicarlo con éxito en el campo; razón por la cual la preparación de las muestras de heces se realizó en agua destilada de manera similar a los antecedentes donde se evaluó el kit FASCIDIG ${ }^{\oplus}$ en el Perú (Torrel 1997; Colona et al. 2001; Castro et al. 2002). Este procesamiento influyó en los resultados obtenidos en la prueba de contrainmunoelectroforesis (CIEF), en la cual ninguna muestra problema resultó positiva. Estos resultados responden a la falta de utilización de un buffer de extracción (compuesto de un tampón fosfato salino suplementado con Tween 20 y azida de sodio), tal como lo realizaron Youssef et al. (1991) y Cornejo et al. (1994), para diluir las muestras de heces a emplear en la CIEF. Sin embargo al realizarse la corrida, los controles positivos (antígenos de excreción-secreción diluidos en PBS), a la par que las muestras problemas, los controles positivos precipitaron de forma óptima a lo reportado como diagnóstico positivo de la fasciolasis por CIEF.

La sensibilidad del ELISA sándwich indirecto propuesto fue de $100 \%$, pero debido al reducido número de muestras positivas por este método y el examen coproparasitológico directo, dicho valor puede estar sobredimensionado, lo cual se evidencia en la reducción del valor predictivo positivo en un 50\%. La sensi- bilidad del kit FASCIDIG ${ }^{\oplus}$, fluctúa entre 60 y 98.7\% (Torrel 1997; Colona et al. 2001, Castro et al. 2002); en donde el valor más alto corresponde a lo reportado por Torrel (1997), el cual a diferencia de otros autores compara el kit FASCIDIG ${ }^{\circledR}$ con el examen de necropsia. Además, reportaron una mayor cantidad de muestras positivas por necropsia comparado con el análisis coproscópico. Colona et al. (2001) y Castro et al. (2002), reportan como valores predictivos positivos 53 y $58 \%$, respectivamente; al comparar el kit FASCIDIG ${ }^{\oplus}$ con el examen coproparasitológico de concentración de Dennis.

La especificidad y el valor predictivo negativo del ELISA sándwich indirecto fue de 96.6\%. Torrel (1997), reporta una especificidad del $100 \%$ para el kit FASCIDIG ${ }^{\bullet}$ con relación al examen de necropsia. Colona et al. (2001) y Castro et al. (2002), reportaron una especificidad del 70\%, y valores negativos de 74 y $90 \%$, respectivamente; al comparar el FASCIDIG ${ }^{\circledast}$ con el examen coproparasitológico de concentración de Dennis.

La especificidad de la contrainmunoelectroforesis (CIEF) comparada con el examen coproparasitológico directo fue de $100 \%$, ya que la CIEF no determinó muestras positivas; este valor de la especificidad se observa aumentado debido a la reducción del valor predictivo negativo (96.7\%). Cornejo et al. (1994), evaluaron las técnica de sedimentación por gravedad (método de Lumbreras) y la contrainmunoelectroforesis (CIEF) para la observación de huevos y la detección de coproantígenos del parásito, respectivamente. De las 106 muestras que evaluaron 13 fueron positivas solo por CIEF, determinando una especificidad de $87.7 \%$; esto se relaciona con el número de muestras analizadas y el empleo del buffer de extracción en la preparación de las muestras.

Al comparar la contrainmunoelectroforesis (CIEF) con el ELISA sándwich indirecto se obtuvo una especificidad de $93.5 \%$, esto se encuentra en relación al resultado positivo de las muestras evaluadas, las cuales para la CIEF fueron falso- positivas lo que redujo la especificidad del ELISA sándwich indirecto (93.5\%) respecto a la CIEF. El valor predictivo negativo del ELISA sándwich respecto a la CIEF fue de $100 \%$, porque las muestras negativas para ambas coincidieron con el número de muestras negativas por CIEF.

Los valores de sensibilidad, especificidad, valor predictivo negativo y positivo, reportados por Torrel 1997; Colona et al. 2001 y Castro et al. 2002, constituyen los referentes más cercanos de comparación, pese a que dichos autores en su momento se enfrentaron con la complejidad de los factores que implica la evaluación de un kit en el campo, y que trascienden los alcances del presente trabajo.

En conclusión el método de ELISA sándwich indirecto desarrollado permite detectar antígenos metabólicos en muestras de heces de ovinos en los estadios prepatente y patente de la infección, aunque se requiere mejorar el proceso de extracción de los antígenos metabólicos y evaluar una mayor cantidad de muestras.

\section{Agradecimientos}

Al Jefe y los miembros del Departamento de Protozoología, Helmintología e Invertebrados del Museo de Historia Natural de la Universidad Nacional Mayor de San Marcos por la colaboración prestada en esta investigación. 


\section{Literatura citada}

Abou-El-Doubal S., Hassan S. Toaleb N., Hegazi A. \& Abdel-Rahman E. 2015. Induction of Protective Cellular and Humoral Responses against Fasciolosis in Rabbits using Immunoaffinity Fraction of Fasciola gigantica Excretory Secretory Products. J Clin Cell Immunol. 6(1): 1-7. DOI: http:// dx.doi.org/10.4172/2155-9899.1000296

Almazan C., G. Avila, H. Quiroz, F. Ibarra \& P. Ochoa. 2001. Effect of parasite burden on the detection of Fasciola hepatica antigens in sera and feces of experimentally infected sheep. Veterinary Parasitology (97): 101-112. DOI: http://dx.doi. org/10.1016/S0304-4017(01)00376-4

Beltrán Fabián de Estrada, María ; Tello Casanova, Raúl ; Náquira Velarde, César. Manual de procedimientos de laboratorio para el diagnóstico de los parásitos intestinales del hombre Lima : Ministerio de Salud, Instituto Nacional de Salud, 2003. 90 p Serie de Normas Técnicas; 37)

Castro J., J. Yoverá \& E. Colona. 2002. Detección de coproantígenos de Fasciola hepatica en vacunos mediante un sándwich-ELISA. Rev. per. Parasitol. 16(1): 10-13

Colona E., L. Alzamora \& J. Castro. 2001. Evaluación de antígenos de Fasciola hepatica por tres métodos inmunológicos. Revista peruara de Biología 8(2): 10-14. DOI: http://dx.doi. org/10.15381/rpb.v8i2.6717

Carnevale S., M. Rodríguez, G. Santillan, J. Labbe, M. Cabrera, E. Bellegarde, J. Velásquez, J. Trgovcic \& E. Guarnera. 2001. Immunodiagnosis of Human Fascioliasis by an EnzymeLinked Immunosorbent Assay (ELISA) and a Micro-ELISA. Clinical and Diagnostic Laboratory Immunology. 8(1): 174 -177. DOI: http://dx.doi.org/10.1128/cdli.8.1.174177.2001

Cornejo W., O. Contreras, A. Huiza \& F. Naquira. 1994. Diagnóstico de fasciolosis humana mediante la detección de coproantígenos usando contrainmunoelectroforesis. Revista Peruana de Parasitología 14(2): 81-83.

Cornelissen B., P. Gaasenbeek, W. Boersma, H. Borgsteede \& J. Van Milligen . 1999. Use of pre-selected epitope cathepsin -L1 in a highly specific peptide-based immunoassay for the diagnosis of Fasciola hepatica infection in cattle. Int. J. Parasitol. 29: 685 - 696. DOI: http://dx.doi.org/10.1016/ S0020-7519(99)00017-X

Domenech I., R. Marcet, M. Figueredo \& J. Sarracent. 2009. Conservación de heces humanas para la detección de antígenos de excreción-secreción de Fasciola hepatica. Comunicación breve. Revista Cubana de Medicina Tropical 61(2):p. 5.

Espino A. \& C. Finlay. 1994. Sandwich enzyme-linked immunosorbent assay for detection of excretory-secretory antigens in human fascioliasis. J Clin Microbiol. 32(1): 190-193.

Espino A., R. Marcet \& C. Finlay. 1990. Detection of circulating antigen in human fascioliasis by sandwich enzyme-linked immunosorbent assay. J Clin Microbiol. 28(12): 2637-2640.

Espino A., A. Díaz, A. Pérez \& C. Finlay. 1998. Dynamics of antigenemia and coproantigens during a human F. hepatica outbreak. J. Clin. Microbiol. 36(9): 2723-2726.

Espinoza J., A. Terashima, P. Herrera-Velit \& L. Marcos. 2010. Fasciolosis humana y animal en el Perú: impacto en las economías de las zonas endémicas. Revista Peruana de Medicina Experimental y Salud Publica 27(4): 604-612. DOI: http:// dx.doi.org/10.1590/S1726-46342010000400018

Estuningsih E., T. Spithill, H. Raadsma, R. Law, G. Adiwinata, E. Meeusen \& D. Piedrafita. 2009. Development and application of a fecal antigen diagnostic sandwich ELISA for estimating prevalence of Fasciola gigantica in cattle in central Java, Indonesia. Journal of Parasitology. 95(2): 450-455. DOI: http://dx.doi.org/10.1645/GE-1672.1

Fuentes Paredes F., R.A. Mendoza Yanavilca, A.L. Rosales Fernández y R.A. Cisneros Tarmeño. 2008. Guía de manejo y cuidado de animales de laboratorio: ratón. Lima: Ministerio de Salud, Instituto Nacional de Salud. 52 pp.
Fuentes Paredes F., R.A. Mendoza Yanavilca, R. Rivera Rodríguez y M.D. Vara Márquez. 2010. Guía de manejo y cuidado de animales de laboratorio: conejo. Lima: Ministerio de Salud, Instituto Nacional de Salud. 48 pp.

Maco V., L. Marcos, A. Terashima, F. Samalvides, E. Miranda, J. Espinoza \& E. Gotuzzo. Fas2-ELISA y la técnica de sedimentación rápida modificada por Lumbreras en el diagnóstico de la infección por Fasciola hepatica. Revista Medica Herediana 13(2): 49-57.

Maleewong W., C. Wongkhan, P. Intapan \& V. Pipitgool. 1999. Fasciola gigantica specific antigens: purification by a continuouselusion method and its evaluation for the diagnosis of human Fascioliasis. Am. J. Trop. Med. Hyg. 61: 648 - 651.

Marcos L., A. Terashima, G. Leguia, M. Canales, J. Espinoza \& E. Gotuzzo. 2007. La Infección por Fasciola hepatica en el Perú: una Enfermedad Emergente. Revista de Gastroenterología del Perú 27: 389-396.

Morilla A. \& C. Bautista. 1986. Manual de Inmunología. Primera Edición. Editorial DIANA (México). ISBN: 968-13-1578-2.

National Research Council (US), Committee for the Update of the Guide for the Care and Use of Laboratory Animals. 2011. Guide for the Care and Use of Laboratory Animals. 8th ed. The National Academies Collection: Reports Funded by National Institutes of Health. Washington (DC): National Academies Press (US). http://www.ncbi.nlm.nih.gov/books/ NBK54050/.

Ochoa R., J. Martínez, X. Ferriol, A. Margarita, E. Estrada, R. Blanco, T. Licea \& F. Sotolongo. 2001. Sensibilización de placas para ensayos inmunoenzimáticos con antígenos vacunales. VacciMonitor. 10(4): 14-17.

Rivera M., C. Rodríguez, Y. Rojas, Y. Valdivia \& T. Saucedo. 2010. Conocimientos, actitudes y prácticas sobre Fascioliasis en madres de una zona rural andina del norte peruano. Revista Peruana de Medicina Experimental y Salud Publica 27(1): 59-62.

Sánchez-Andrade R., A. Paz-silva, J. Suárez, R. Panadero, P. Diez-Ba-os P. \& P. Morrondo. 2000. Use of a sandwich-enzyme-linked immunosorbent assay (SEA) for the diagnosis of natural Fasciola hepatica infection in cattle from Galicia (NW Spain). Veterinary Parasitology. 9: 39-46. DOI: http:// dx.doi.org/10.1016/S0304-4017(00)00326-5

Shafiei R., Sarkari B. \& Mahmoud Sadjjadi S. 2015. Performance of a $27 \mathrm{kDa}$ Fasciola hepatica Antigen in the Diagnosis of Human Fascioliasis. Journal of Laboratory Physicians. 7(1): 17-20. DOI: http://dx.doi.org/10.4103/0974-2727.154781

Ticona D., A. Chávez, G. Casas, A. Chavera \& O. Li. 2010. Prevalencia de Fasciola hepatica en bovinos y ovinos de Vilcashuamán, Ayacucho. Revista de Investigaciones Veterinarias del Perú 21(2): 168-174

Torrel T. 1997. Detección de coproantígenos de Fasciola hepatica en ovinos y bovinos mediante un método de ELISA. Rev Inv Pec IVITA (Perú).8(1): 74-78.

Torrico D. 2000. "Determinación de anticuerpos anticitoplasma de neutrofilo (ANCA) por inmunofluorescencia indirecta (IFI)". Gómez, Patricia \& Calla, Jacqueline. Tesis para optar el grado de Especialista en Diagnóstico en Salud, mención Hematología. Facultad de Ciencias Farmaceúticas y Bioquímicas. Universidad Mayor de San Andres. La Paz-Bolivia.

Youssef F., M. Mansour \& A. Aziz. 1991. Early diagnosis of human fascioliasis by the detection of copro-antigens using counterimmunoeiectrophoresis. Transactions of the Royal Society of Tropical Medicine and Hygiene. 85: 383-384. DOI: http://dx.doi.org/10.1016/0035-9203(91)90300-N 